\title{
Scientometric Survey of Human Heart Disease Related Publications in ASEAN, the Philippines and Singapore
}

\author{
Christian Derrick Q. Lapuz, Carl Adrian M. San Jose, Athos Jacob M. Marasigan \\ and Madhavi Devaraj ${ }^{2 *}$ \\ School of Information Technology, Mapúa University, Manila, Philippines \\ cedric550_lapuz@gmail.com,csanjose0310@gmail.com, \\ marasiganathos@gmail.com,mdevaraj@mapua.edu.ph, \\ madhavidevaraj@gmail.com
}

\begin{abstract}
This paper presents a scientometric survey of heart disease related publications that were done in ASEAN countries, the Philippines and Singapore from 2000-2017. The research were performed using the Scopus database where we got the indexed records needed for the survey. This survey includes the prominent findings such as research output of ASEAN countries, and also the comparison of cited and uncited papers. It also includes some of the prominent publications, growth trend and impact of each country and finding out research trend analysis by key word search. The results of this research would help the future researchers on which of the researches are effective and has an impact growth as years go by.
\end{abstract}

Keywords: Bibliometrics, Survey, Human Heart Disease, Research Impact, ASEAN, Scientometric, Mapping, Philippines, Singapore

\section{Introduction}

Scientometric is a [18] tool which is used to study and analyze the quality and impact of different scientific productions (articles, journals, dissertation, etc.). [1,6] This field of science is very essential because it can be crossed or used in almost the different kinds in field of science such as webometrics, bibliometrics, and altmetric. [2] Disease is an abnormal state in the body where it can cause implications and affect our health. There are categories in which diseases can be known, it could be autoimmune, bacterial, blood, cancer, digestive, heart, nerve (or neurodegenerative), sexually transmitted or thyroid. Diseases could be classified wherein it can be passed or diseases that can't be passed to other living organism. The importance of knowing the kinds of diseases will give us the ability to have an advantage of avoiding and curing them. Diseases could be avoided with using good habits including ensuring that the body stays clean, having to eat nutritious food, frequent exercise and getting regular shots of medicine that the body needs. Treatments of diseases can be done from just taking medication to having to undergo surgery for complete repair of the affected part in the body. There are diseases that can be healed by time, while others undergo a set of treatments where in some cases it is also unsure of being effective. [3]. Health Research is done to gain more knowledge about human health. Human health does also contribute to the discovery of new possible cure for diseases. Health research also gave way for the advancement of how we care and give treatments to the people globally. Medical care is the way the doctors treats the illness that you have. [4]. its only purpose is to make you feel better and you receive direct benefits. On the other hand, medical research studies are done to learn about and to improve current

Received (May 6, 2017), Review Result (July 8, 2017), Accepted (August 25, 2017)

*Corresponding Author (e-mail: mdevaraj@ mapua.edu.ph ; madhavidevaraj@gmail.com) 
treatments. We all benefit from the new knowledge that is gained in the form of new drugs, vaccines, medical devices (such as pacemakers) and surgeries.

\section{Related Work and Implications}

The aim of this research is to concentrate in health related studies occurring in the ASEAN countries. There have been research collaboration in Southeast Countries where the analysis is done on several important parameters such as total research production, global share and rank, subject categories, citation impact, in and out-region citation patterns, and other inter- country collaborations. [5] The aim of this survey is to analyze heart disease related publications in ASEAN countries with the help of scientometric indicators. scientometrics is quite new in the Philippines as a research topic because only quite a few tried to create it in the country. Wherein compared to [13] Mexico which ranks $35^{\text {th }}$ in the world CS research Output during the periods of 1989-2014, they have already made some systematic computational analysis to characterize CS research. $[6,10,12]$ The ASEAN countries, despite lagging behind in Science and Technology sector development during the second half of the 20th century, made noticeable progress in the IT sector in the recent past. IT has gradually become one of the largest services sector contributors to economies of the region and one of the major employment providers. However, at the same time, it is also true that the region lacks the effort toward the development of original hardware and software products and services. [7] This has been proven by a query placed in the Scopus Database by Elsevier in the subject of scientometrics with Philippines as an affiliated country, which yielded a 200 datasets related to health researches. [11, 14-16] From these writings, particularly the paper of Uddin, Singh, Pinto et al. [1,17] Our group were able to extract and able to utilize their techniques in order to create this research. By also using the book "Scientometrics" by the De Bellis it aide us and give us a far idea of what is scientometric.

\section{Data Collection}

Scopus database was used to collect relevant publications on human health-related research in ASEAN countries in years 2000 - 2017. [8] Scopus has also been used to help the emerging research of the 'Big Data' by Vivek Kumar Singh et al., which is one of the most important emerging areas of research in computational sciences. [7] The document type of the data set is limited to Articles, Review, Conference Paper and Editorial and is published in ASEAN countries (Brunei, Cambodia, Indonesia, Laos, Malaysia, Myanmar, Philippines, Singapore, Thailand and Vietnam). The main focus of this research will be the point of comparison with the counties of Philippines and Singapore. To find the exact the data needed the researchers used the same (TITLE-ABS-KEY) query but different country tags and the country's heart disease related. The searched query of the heart disease research must contain the words required if the downloaded dataset does not have the words contain in their title, abstract, keyword, the country and their top disease related will be disregarded and remove from the dataset. 
Table 1. Datasets Gathered from ASEAN Countries

\begin{tabular}{|c|c|}
\hline Country & Datasets \\
\hline Singapore & 1,873 data \\
\hline Thailand & 1,173 data \\
\hline Malaysia & 792 data \\
\hline Philippines & 188 data \\
\hline Indonesia & 152 data \\
\hline Laos & 10 data \\
\hline Brunei & 24 data \\
\hline Cambodia & 15 data \\
\hline Vietnam & 0 data \\
\hline Myanmar & 5 data \\
\hline
\end{tabular}

\section{Research Output and Global Share}

The research output and the [9] global shares of Health related papers and its relation with heart diseases were the first parameters this research attempted to measure and analyze. This process has been done in different methods: First, the rankings of the heart related topics where it went through data cleaning from raw data. After the data cleaning it was then arranged in ranks. It showed that Singapore yields the most papers in the region with 1873 raw data as shown in Table 1. Second, we categorized the papers by each countries according to their publication such as for articles, review, conference paper and editorial. In Table 2 it shows that Thailand sets the highest published articles with 1005 papers, followed by Malaysia with the most published reviews. Most of the conference papers were from Malaysia also with 142 and lastly the Editorial papers were also published in Malaysia. Another method used was the growth of the papers in every country on a block of 6 years which can be seen on Table 4 , where Thailand tallied up the most growth in papers with 1172. Another method is the use of Citations that were used to publish each papers, in which Singapore has the most cited publications. We also categorized the papers which are cited and uncited in blocks of 6 years each country, most of the uncited papers where from Malaysia and the most cited is Thailand as seen on Table 5. Lastly, we used a measuring parameter with the use of the percentage of cited and uncited papers of ASEAN countries where in Table 6 yields the output. The total research output of the countries of Singapore and Philippines were compared. Where as seen in Table 7, both of the countries have increased in the numbers of outputs in the numbers of years.

Table 2. Unranked and Unranked Heart Related Disease Topics

\begin{tabular}{|lcclcc|}
\hline Country & Raw & Clean & Top Country & Raw & Clean \\
\hline Brunei & 24 & 12 & Singapore & 1873 & 863 \\
\hline Cambodia & 15 & 5 & Thailand & 1176 & 1172 \\
\hline Indonesia & 152 & 96 & Malaysia & 792 & 782 \\
\hline Laos & 10 & 10 & Indonesia & 152 & 96 \\
\hline Malaysia & 792 & 782 & Philippines & 200 & 188 \\
\hline Myanmar & 5 & 5 & Brunei & 24 & 14 \\
\hline Philippin€ & 200 & 188 & Cambodia & 15 & 5 \\
\hline Singapore & 1873 & 863 & Laos & 10 & 10 \\
\hline Thailand & 1176 & 1172 & Myanmar & 5 & 5 \\
\hline Vietnam & 0 & 0 & Vietnam & 0 & 0 \\
\hline Total & 4247 & 3133 & Total & 4247 & 3133 \\
\hline
\end{tabular}


Table 3. Used Documents in Each country

\begin{tabular}{|c|c|c|c|c|c|}
\hline Country & Article & Review & Conference Paper & Editorial & Total \\
\hline Brunei & 8 & 4 & 0 & 0 & 12 \\
\hline Cambodia & 4 & 0 & 1 & 0 & 5 \\
\hline Indonesia & 84 & 16 & 1 & 0 & 101 \\
\hline Laos & 9 & 0 & 1 & 0 & 10 \\
\hline Malaysia & 612 & 142 & 15 & 13 & 782 \\
\hline Myanmar & 5 & 0 & 0 & 0 & 5 \\
\hline Philippines & 159 & 25 & 4 & 0 & 188 \\
\hline Singapore & 715 & 137 & 11 & 0 & 863 \\
\hline Thailand & 1005 & 141 & 18 & 8 & 1172 \\
\hline Vietnam & 0 & 0 & 0 & 0 & 0 \\
\hline Total: & & & & & 3138 \\
\hline
\end{tabular}

Table 4. Years Growth for All Countries

\begin{tabular}{lccccc|}
\multicolumn{5}{c}{ Years } & \\
\hline \multicolumn{1}{c}{ Country } & 2000-2005 & 2006-2011 & 2012-2017 & Total \\
\hline Brunei & 1 & 7 & 4 & 12 \\
\hline Cambodia & 1 & 2 & 2 & 5 \\
\hline Indonesia & 14 & 21 & 61 & 96 \\
\hline Laos & 0 & 5 & 5 & 10 \\
\hline Malaysia & 88 & 268 & 426 & 782 \\
\hline Myanmar & 1 & 2 & 2 & 5 \\
\hline Philippines & 23 & 73 & 92 & 188 \\
\hline Singapore & 150 & 282 & 431 & 863 \\
\hline Thailand & 277 & 412 & 483 & 1172 \\
\hline Vietnam & 0 & 0 & 0 & 0 \\
\hline Total: & & & & 3133 \\
\hline
\end{tabular}

Table 5. Overall Citations Used for each Published Papers

\begin{tabular}{|c|c|c|c|c|}
\hline \multicolumn{5}{|c|}{ Overall citation used for each publish papers } \\
\hline Country & 2000-2005 & 2006-2011 & 2012-2017 & Total \\
\hline & Cited & Cited & Cited & Cited \\
\hline Brunei & 32 & 110 & 14 & 156 \\
\hline Cambodia & 2 & 362 & 7 & 371 \\
\hline Indonesia & 175 & 1919 & 448 & 2542 \\
\hline Laos & 0 & 129 & 15 & 144 \\
\hline Malaysia & 2481 & 9256 & 4796 & 16533 \\
\hline Myanmar & 5 & 79 & 7 & 91 \\
\hline Philippines & 281 & 6187 & 2083 & 8551 \\
\hline Singapore & 5775 & 13926 & 13031 & 32732 \\
\hline Thailand & 9018 & 12381 & 4493 & 25892 \\
\hline Vietnam & 0 & 0 & 0 & 0 \\
\hline Average Citation use: & 1776.9 & 4434.9 & 2489.4 & 8701.2 \\
\hline
\end{tabular}


Table 6. Cited and Uncited Research Papers of ASEAN Countries

\begin{tabular}{|c|c|c|c|c|c|c|c|c|}
\hline \multicolumn{9}{|c|}{ Cited and Uncited Research papers } \\
\hline \multirow[t]{2}{*}{ Country } & \multicolumn{2}{|c|}{$2000-2005$} & \multicolumn{2}{|c|}{ 2006-2011 } & \multicolumn{2}{|c|}{ 2012-2017 } & \multicolumn{2}{|c|}{ Total } \\
\hline & Cited & Uncited & Cited & Uncited & Cited & Uncited & Cited & Uncited \\
\hline Brunei & 1 & 0 & 7 & 0 & 2 & 2 & 10 & 2 \\
\hline Cambodia & 1 & 0 & 2 & 0 & 1 & 1 & 4 & 1 \\
\hline Indonesia & 9 & 5 & 19 & 2 & 61 & 13 & 89 & 20 \\
\hline Laos & 0 & 0 & 4 & 1 & 4 & 1 & 8 & 2 \\
\hline Malaysia & 78 & 10 & 234 & 34 & 337 & 89 & 649 & 133 \\
\hline Myanmar & 1 & 0 & 2 & 0 & 1 & 1 & 4 & 1 \\
\hline Philippines & 21 & 2 & 60 & 13 & 67 & 25 & 148 & 40 \\
\hline Singapore & 145 & 5 & 267 & 15 & 373 & 58 & 785 & 78 \\
\hline Thailand & 254 & 23 & 376 & 36 & 469 & 14 & 1099 & 73 \\
\hline Vietnam & 0 & 0 & 0 & 0 & 0 & 0 & 0 & 0 \\
\hline
\end{tabular}

Table 7. Percentage of Cited and Uncited in ASEAN Countries

\begin{tabular}{|lcccc|}
\multicolumn{5}{c}{ Asean } \\
Years & Cited & Uncited & \%Cited & \&Uncited \\
\hline $2000-2005$ & 510 & 45 & 91.89189 & 8.108108 \\
\hline $2006-2011$ & 971 & 101 & 90.57836 & 9.421642 \\
\hline $2012-2017$ & 1315 & 204 & 86.57011 & 13.42989 \\
\hline
\end{tabular}

Philippines

\begin{tabular}{|ccccc|}
\hline $2000-2005$ & 21 & 2 & 91.30435 & 8.695652 \\
\hline $2006-2011$ & 60 & 13 & 82.19178 & 17.80822 \\
\hline $2012-2017$ & 67 & 25 & 72.82609 & 27.17391 \\
\hline
\end{tabular}

\begin{tabular}{|ccccc|} 
Singapore & & & & \\
\hline $2000-2005$ & 145 & 5 & 96.66667 & 3.333333 \\
\hline $2006-2011$ & 267 & 15 & 94.68085 & 5.319149 \\
\hline $2012-2017$ & 137 & 58 & 70.25641 & 29.74359
\end{tabular}

Table 7. Total Research Output

\begin{tabular}{|c|c|c|c|c|c|}
\hline Period & TP in Singapore & TP in Singapore on Heart-Related & HR as \% of TP in Singapore & TP in ASEAN in world & Sinagpore \% share of \\
\hline $2000-2005$ & 308 & 150 & 48,70 & 737 & 20.35 \\
\hline $2006-2011$ & 672 & 282 & 41.96 & 737 & 38.26 \\
\hline $2012-2017$ & 883 & 431 & 48.81 & 687 & 62.74 \\
\hline Period & TP in Philippines & TP in PH on Heart-Related & HR as \% of TP in Ph & TP in ASEAN in world & Ph's\% share of HR \\
\hline $2000-2005$ & 23 & 103 & 447.83 & 737 & 13.98 \\
\hline $2006-2011$ & 73 & 74 & 101.37 & 737 & 10.04 \\
\hline $2012-2017$ & 92 & 23 & 25,00 & 687 & 3.35 \\
\hline
\end{tabular}

\section{Growth Trend and Impact}

The impact and growth rate of health related papers research output of heart disease was measured for the last 18 years. The data is mapped to blocks of 3, 6 years each to show a more understandable output. The output clearly showed with respect to the 3 
blocks within 6 years. The growth of the health related research mostly happened in the Countries of Singapore and Thailand in the entire years block. Therefore these countries continued their works on such papers where from year 2000 they were able increase the total research output up to now. Similarly to the Country of Malaysia they have also increased their research output about health related papers in the block of (2012-2017). With the use of formula the growth rate for the preceding block can be computed. This results shown that the percentage in the research output for the succeeding blocks percentages have increased.

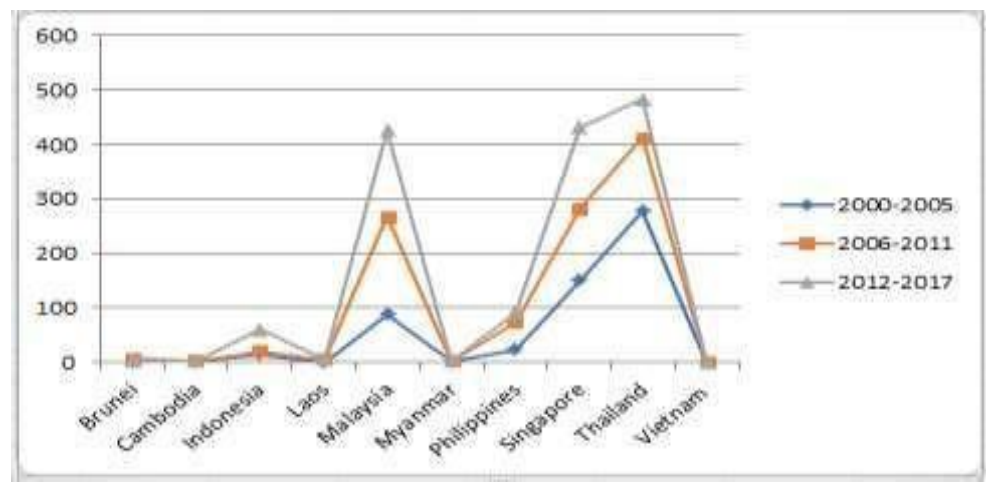

Figure 1. Years Growth for All Countries

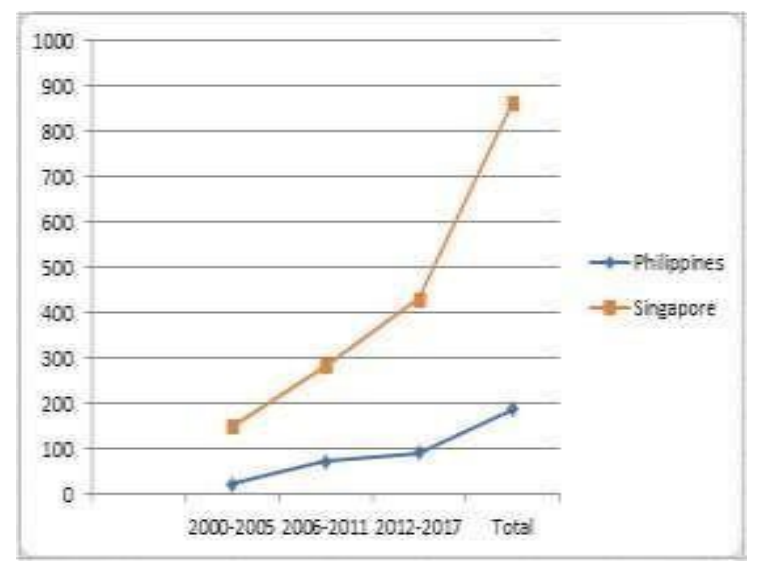

Figure 2. Years Growth between Singapore and Philippines

We wanted to compare the amount of citations with the different countries within the region. It could give an indication of the growth of research in the countries. Figure 3 shows the total growth of all in country in all the years. It is observable that Thailand has the lead numbers in the side of citations especially on 2012-2017. Compared to the other countries within the region, it was compared with other countries except Singapore which has also more growth in terms of research in the past years. 


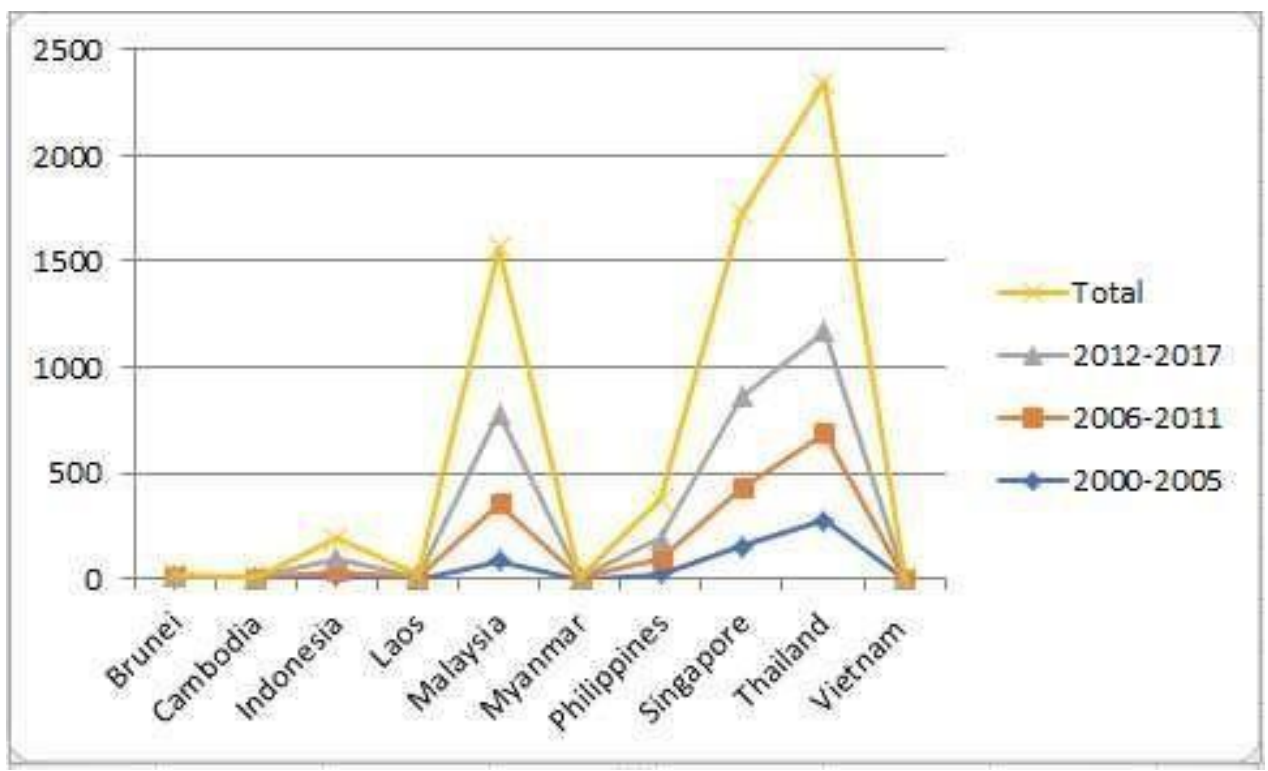

Figure 3. Years Growth with Total in All Countries

\section{Cited vs. Uncited Research Papers}

An output of a research should be looked as helpful and useful if it gets the interests from other researchers which a citation-based analysis could be a way of measuring productive and useful research. Upon doing this, the group measured the "Cited vs. Uncited" years of health related that focuses on heart disease which are found in ASEAN countries. As seen in Figure 4, we calculated the values using a 6 year block of Cited and Uncited papers in every country. Since the country of Singapore has the most papers in a 6 year block, cited and uncited. As seen in Figure 5. It seems the Philippines has not published much health related papers that are neither Cited nor Uncited. Lastly, we also compared the average Citation used in Philippines and Singapore. Figure 6 shows that in every 6 years the health related papers continued to grow more in Singapore than the Philippines.

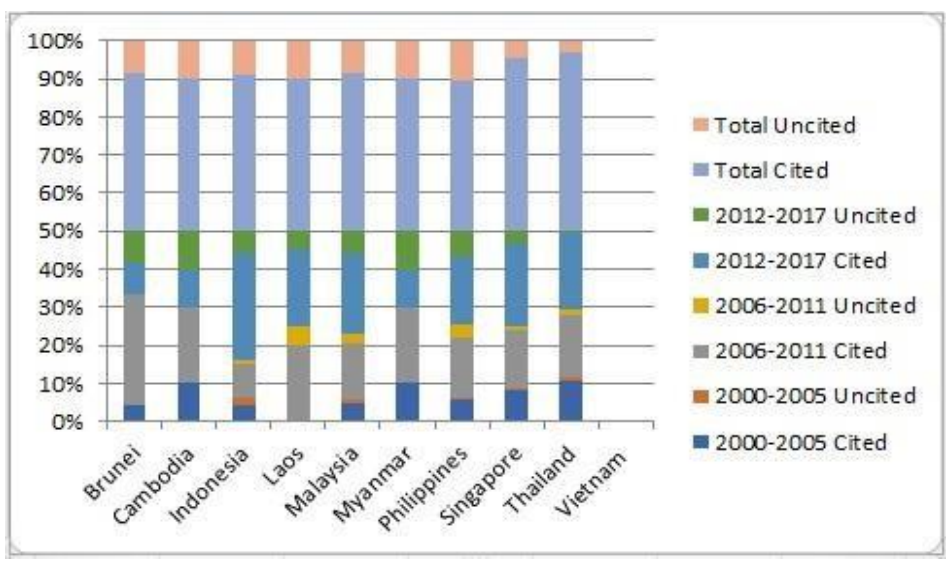

Figure 4. Cited vs. Uncited Years in ASEAN Countries 


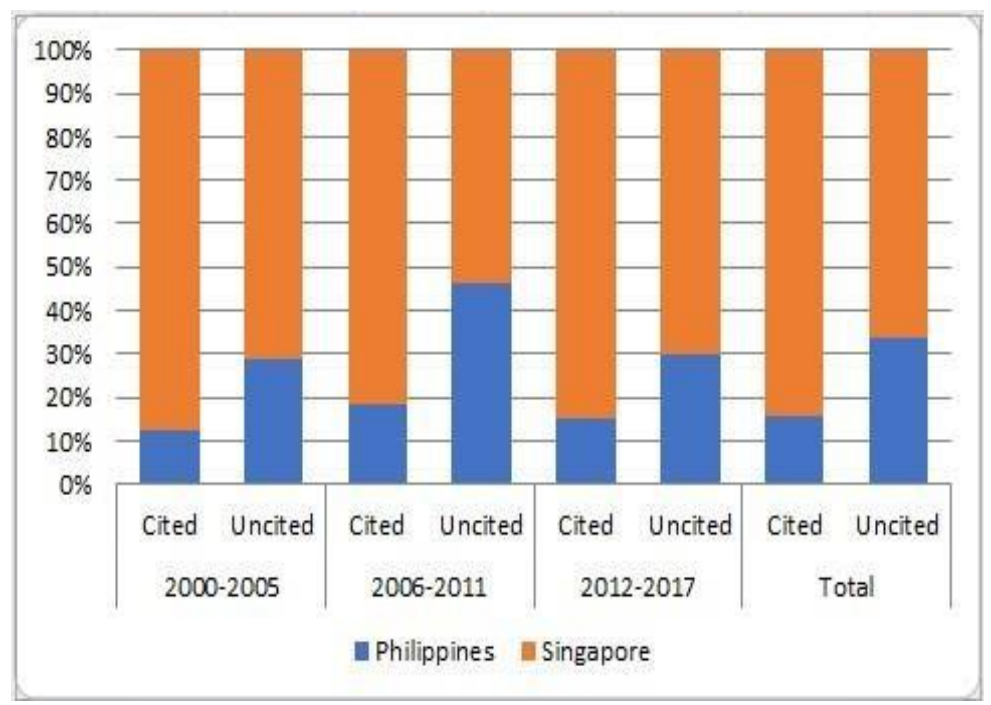

Figure 5. Cited and Uncited Percentage for Philippines and Singapore

Average Citation Use in Philippines and Singapore

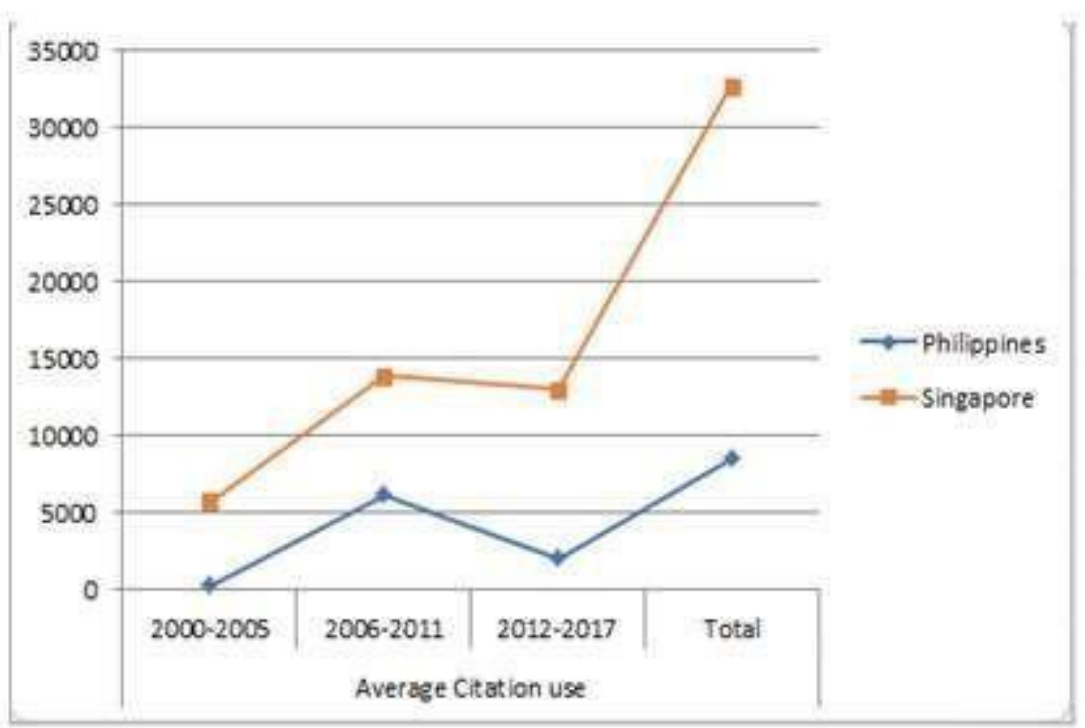

Figure 6. Average Citation Use in Philippines and Singapore

\section{Keyword-Based Research Trend Analysis}

Further, research trend for Health Related papers in the ASEAN Countries were analyzed. There are many areas of research in the Medical Industry especially in the section of diseases and it continue to grow. Therefore, it showed that this research could continue to grow and changes in the trend might be useful in time. In order to get a visual of this, "Health related keywords" were used to gather if each of the paper would be valid. By sorting all the datasets of all ASEAN countries we we're able to create a word cloud from years ranging from 2000-2005, 2006-2011 and 2012-2017. 


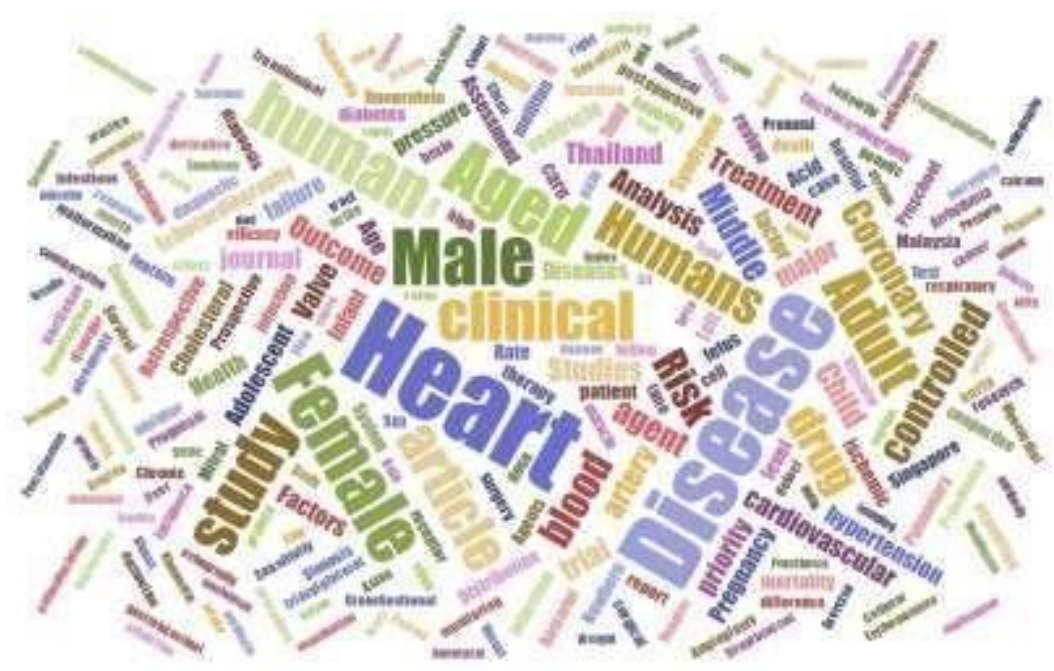

Figure 7. Word Cloud of 2000-2005

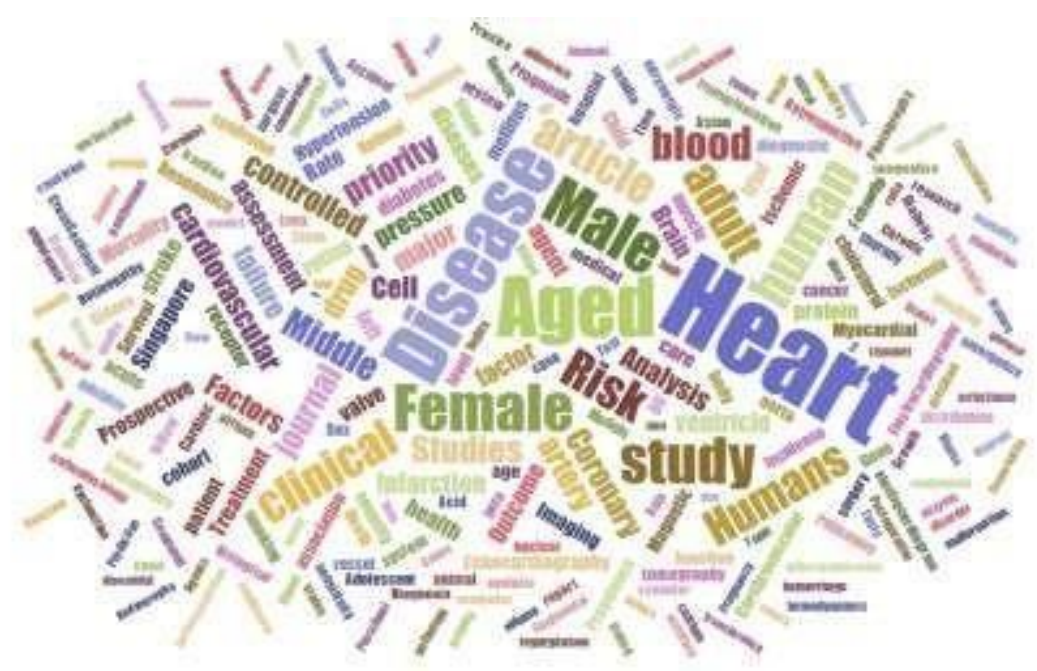

Figure 8. Word Cloud of 2006-2011

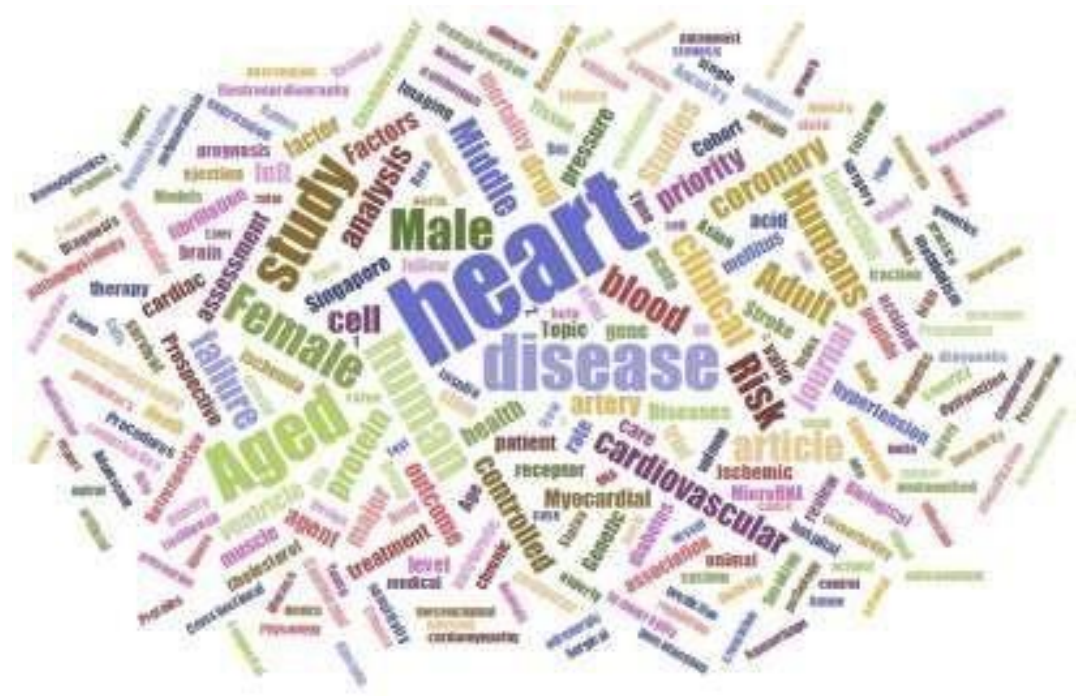

Figure 9. Word Cloud of 2012-2017 


\section{Conclusion}

This article illustrates scientometric analysis of heart disease related publications on ASEAN countries especially Singapore and Philippines. Prominent results gained from this this research were total research output, global share, growth trends and impact, citation proportion, and research trends of ASEAN countries. The survey was able to compare the outcome from Philippines and Singapore with the outputs of the participating ASEAN countries. By describing and analyzing the citation counts and pattern, this research will calculate the impact and the growth of research year-by-year by the ASEAN countries.

The outcome from this research will be utilized in order to assess the health related studies especially heart disease which is occurring in ASEAN countries and the Philippines, in addition to other things. This may likewise help and contribute to improve the collaboration levels. It is imperative to not remain inside the limits of your own country while delivering a research, collaboration with other nations or societal norms can be beneficial in creating a more useful and universal output coordinated effort with different countries or societal standards can be advantageous in making a more valuable and general yield. Health research studies is very important and has an impact of research especially students who are studying about medicine it can also have a global effect, so it is very essential for others. The importance for this is for future growth and could boost research outputs on this specific field.

\section{References}

[1] N. De Bellis, Bibliometrics and citation analysis, 1st ed. Lanham, Md.: Scarecrow Press, (2009).

[2] Healio.”What are diseases?". 2012.[Online]http://www.healio.com/infectious disease/news/online/\%7B53e2cad9 -f420-4d59-ad86-6a61e8d7586f\%7D/what -are-diseases

[3] Provalis."What are Scientometrics and Bibliometrics?". 2013.[Online] https://provalisresearch.com/solutions -2/applications/scientometrics -bibliometrics-software/

[4] Countway Library of Medicine, "What is health Research?", Countway Library Guide to Participating in Health Research , 2017. [Online]. http://guides.library.harvard.edu/healthresearch [Accessed: 28 -May2017].

[5] A. Uddin and V. K. Singh, "Measuring research output and collaboration in South Asian Countries", Current Science, vol. 107, no. 1, (2014), pp. 10.

[6] A. Uddin, V. K. Singh and D. P into, "Scientometrics", vol. 105, (2015), pp. 97.

[7] K. Singhal, S. K. Banshal, A. Uddin and V. K. Singh, "The information technology knowledge infrastructure and research in South Asia”, Journal Sci. Res., vol. 3, (2014), pp. 134 -42.

[8] Vivek Kumar Singh, Sumit Kumar Banshal, Khushboo Singhal, and Ashraf Uddin. 2015. Scientometric mapping of research on 'Big Data'. Scientometrics 105, 2 (November 2015), 727 -741.

[9] Ashraf Uddin \& Vivek Kumar Singh (2014): Mapping the Computer Science Research in SAARC Countries,IETE Technical Review, DOI: 10.1080/02564602.2014.947527

[10] Uddin, A., Singh, V.K. Measuring research output and collaboration in South Asian countries, (2014).

[11] A. Uddin \& V. K. Singh (2015): A Quantity-Quality Composite Ranking of Indian Institutions inCS Research, IETE Technical Review, DOI: 10.1080/02564602.2015.1010614

[12] Singhal, K.,Banshal,S.K.,Uddin, A., \& Singh, V.K. (2014) The information technology knowledge infrastructure and research in South Asia

[13] Uddin, A, Singh, V.K.,Pinto,D.,\& Olmos,I. (2015). Scientometric mapping of computer science research in Mexico. DOI 10.1007/s11192-015-1654-y

[14] Uddin, A., Bhoosreddy,J., Tiwari,M., \& Singh, V.K.(2015). A Sciento-text framework to characterize research strength of institutions at fine-grained thematic area level

[15] A. Basu and R. Aggarwal, "Internation coloration in science in India and its impact on institutional performance", Scientometrics, vol. 52, no. 3, pp. 379 -394, 2001.

[16] A. Basu, S. Banshal, K. Singhal and V. Singh, "Designing a Composite Index for research performance evaluation at the national or regional level: ranking Central Universities in India", Scientometrics, vol. 107, no. 3, pp. $1171-1193,2016$.

[17] N. Shirakawa, T. Furukawa, K. Hayashi and M. Tamamura, "Double-loop bench marking methods in the era of data deluge: An empirical scientometric study and assessment of Japan's Galapagos syndrome in scientific research activities," Proceedings of PICMET '14 Conference: Portland International Cente r for Management of Engineering and Technology; Infrastructure and Service Integration, Kanazawa, (2014), pp. $2799-2806$. 
[18] A. Basu and V. Kumar, "International collaboration in Indian specific papers", Scientometrics, vol. 48, no. 3, (2000), pp. $381-402$.

[19] M. Singh and N. Hasan, "Trend in research output and collaboration pattern among BRICS countries: A scientometric study", 2015 4th International Symposium on Emerging Trends and Technologies in Libraries and Information Services, (2015).

\section{Authors}

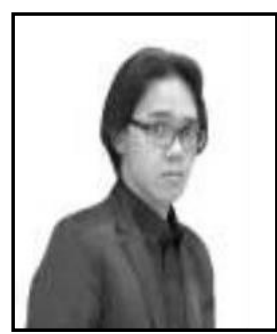

Christian Derrick Q. Lapuz, is currently an undergraduate student for Bachelor of Science in Computer Science - Mapúa University, Manila, Philippines. His research interest is in scientometric, text analytics, machine learning and sentiment analysis. Email: cedric550_lapuz@gmail.com

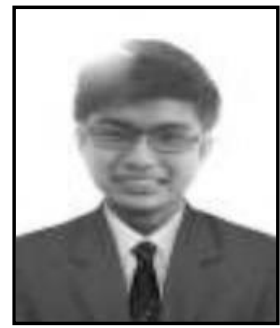

Carl Adrian M. San Jose, is currently an undergraduate student for Bachelor of Science in Computer Science - Mapúa University, Manila, Philippines. His research interest is in scientometric, text analytics, machine learning and sentiment analysis. Email: csanjose0310@gmail.com

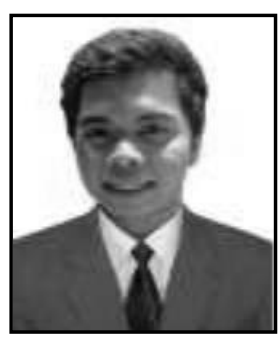

Athos Jacob M. Marasigan, is currently an undergraduate student for Bachelor of Science in Computer Science - Mapúa University, Manila, Philippines. His research interest is in scientometric, text analytics, machine learning and sentiment analysis. Email: marasiganathos@gmail.com

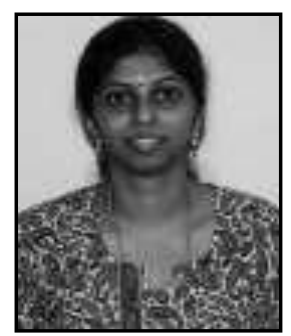

Madhavi Devaraj, received MCA and MPhil degrees in computer science from Madurai Kamaraj University, Madurai, India, and doctoral degree in computer science from Dr. A.P.J Abdul Kalam Technical University, Lucknow, India. She has been assistant professor in computer science department at Invertis University and Babu Banarasi Das University previously. Currently, she is professor in computer science department at Mapúa University, Manila, Philippines. Her research interests include text analytics. Email: mdevaraj@mapua.edu.ph,madhavidevaraj@gmail.com 
International Journal of $u-$ and $\mathrm{e}-$ Service, Science and Technology Vol.10, No.9 (2017) 